\title{
Pili torti-onychodysplasia syndrome
}

INSERM

\section{Source}

INSERM. (1999). Orphanet: an online rare disease and orphan drug data base. Pili tortionychodysplasia syndrome. ORPHA:2890

A rare ectodermal dysplasia syndrome characterized by congenital onychodystrophy (particularly of the distal nail) and severe hypotrichosis with alopecia involving the eyebrows, eyelashes and body hair. Scalp, beard, pubic and axillary hair is brittle and shows a twisting pattern on electron microscopy. There have been no further descriptions in the literature since 1991. 